REVL-1974, núm. 181. MARAÑON BARRIO, MIGUEL. LA SOLIDARIDAD CATALANA ANTE...

\title{
LA SOLIDARIDAD CATALANA ANTE LOS ENSAYOS DE REFORMA LOCAL DE MAURA
}

\author{
323.74:352.047 (091) (46. Cataluña) \\ por \\ Miguel Marañón Barrio
}

SUMARIO: I. INTRODUCCION.-II. EL MARCO HISTORICO DEL PROYECTO DE REFORMA DE LA LEGISLACION LOCAL DE 1907. III. LA «SOLIDARITAT» Y EL IDEARIO DE MAURA.-IV. LA CONTESTACION AL MENSAJE DE LA CORONA.-V. LA CRISIS INTERNA DE LA SOLIDARIDAD.-VI. EL PROYECTO DE 1907: SUS CARACTERISTICAS Y AVATARES.-VII. HACIA UN HORIZONTE REVOLUCIONARIO.

\section{INTRODUCCION}

En la vida de los pueblos existen fechas trascendentales cuya importancia estriba no tanto en la gloria o la exaltación externa que suele acompañar a una resonante victoria o una derrota rayana en el desastre, sino en que suscita por doquier el afán por encontrar la clave última de la convivencia nacional, la razón de ser de ese pueblo como tal colectividad.

La derrota española en la guerra hispano-norteamericana de 1898 y el despojo de los últimos restos del más extenso imperio colonial de la historia, operado por el Tratado de París, abren un período crítico dentro del marco de convivencia política de la Restauración canovista, que puso fin al período revolucionario inicia- 
do en septiembre de 1868 por el levantamiento de Topete, SERrano y PRIM. Todo un capitulo esencial de la historia literaria y política se cubre entonces con el tema de la regeneración: la generación llamada del 1898, estudiada, entre otros, por LAf́N ENTRALGo y GARcf́a EsCUDERo, que se plantea el problema del ser de España; polígrafos, como Costa y Almirall; técnicos, como Mallada o Picavea; políticos del régimen, como Silvela, y militares, como Polavieja. SIlvela mismo, presidente del primer Gobierno subsiguiente al desastre (1898 es el año del «desastre» por antonomasia) habla de un país asin pulso», expresión ésta que hará la más completa fortuna.

Cuatro años más tarde, cuando el joven Alfonso XIII es coronado Rey de España, escribe de puño y letra en su diario íntimo: "Este año me encargué de las riendas del Estado, acto de suma trascendencia tal y como están las cosas, porque de mí depende si ha de quedar en España la Monarquía borbónica o la República. Porque yo me encuentro al país quebrantado por nuestras pasadas guerras; que anhela por un alguien que le saque de esa situación; aplazadas las reformas sociales en favor de los necesitados; el Ejército, con una organización atrasada a los adelantos modernos; la Marina, sin barcos; la bandera, ultrajada; los Gobernadores y Alcaldes, que no cumplen las leyes, etc. En fin, todos los servicios desorganizados y mal atendidos. Yo puedo ser un rey que se llene de gloria regenerando a la Patria, cuyo nombre pase a la historia como recuerdo imperecedero de su reinado; pero también puedo ser un rey que no gobierne, que sea gobernado por sus ministros $y$, por fin, puesto en la fronteras (1).

El país entero hace examen de conciencia. Al intento regeneracionista de Silvela-Polavieja se incorpora por primera vez el movimiento regionalista catalán, representado en el Gobierno por la figura prócer de DURÁN Y BAS. La presencia de este movimiento -nuevo en la vida política activa española - no deja de suscitar fuertes recelos en el partido liberal, que ve con desconfianza cómo se ponen sobre el tapete las famosas bases de Manresa, que adieron forma a un posible Estado Catalán investido de funciones que desbordaban el concepto de autonomía (2). Es también el catalanismo una forma de regeneracionismo nacional. Más adelante vere-

(1) Pablo VIIn SAN-JunN, eAlfonso XIII», I, La Vanguardia Española, 9-III-73.

(2) M. FERNANDEz Almagro, Historia politica de la España contemporanea, volumen 3, Alianza Editorial, Madrid, 1968, pág. 189. 
mos los supuestos filosóficos, políticos y económicos en que su planteamiento descansa.

Una corriente de introversión y de pesimismo invade todos los espíritus y apenas deja asomar un tímido rayo de esperanza. Valgan como expresión de tal estado de ánimo las palabras del MARQUÉS DE LA VEGA DE ARMIJo, que declara en El Liberal (22-IX-1898): «La situación por que está pasando España requiere de todos los partidos un solemne recogimiento que sirva de preparación a recobrar las fuerzas para dedicarnos en paz a la reorganización y aun a la salvación de lo que nos queda dentro de los límites peninsulares» (3). He aquí el origen de la polémica, que aún colea en nuestros días, del ser histórico de España, de su vocación europea, de sus valores autóctonos, de la reconciliación de las «dos Españas». En fin, del "problema nacional" de Silvela, necesitado de "menos política y más administración», ávido de una política de realidades. Costa clamará por un «cirujano de hierro».

Conocido es el papel que en el fracaso del sistema constitucional de 1874 se atribuye al sistema electoral propio del turno de partidos y a la corrupción de la vida local a través del caciquismo. Los nombres de Maura, Calvo Sotelo y ORTEga y Gasset van indisolublemente unidos a la denuncia de este sistema corrupto, así como el de Costa y —esta circunstancia menos conocida- el de Valentí Almirall, que ha dejado en su España como es páginas de insuperable ironía y eficacia en la crítica mordaz del mismo.

Es en el marco de esta crítica del sistema donde hay que situar el intento de Antonio Maura (en sus Proyectos de 1903 y 1907) de reforma de la vida local; intento apasionado, como ha recordado Antonio Carro, que iba íntimamente unido en su autor a la convicción de que habría de plantearse simultáneamente con una reforma de la legislación electoral.

En los mentados Proyectos de MAURA aparece configurada seriamente, por vez primera en nuestra Patria, la idea de región autónoma a través de la figura jurídica de las Mancomunidades. Conoció esta idea en los años que nos ocupan una excepcional oportunidad de mostrar su funcionalidad real dentro del sistema, pues coincidió con el movimiento de Solidaritat Catalana, que introdujo por vez primera en las Cortes una fuerte minoría regionalista, dinástica y conservadora en parte $\mathrm{y}$, en todo caso, bajo la guía indis-

(3) M. Fernandez almagro, op. cit.; pág. 194. 
REVL-1974, núm. 181. MARAÑON BARRIO, MIGUEL. LA SOLIDARIDAD CATALANA ANTE...

cutible de la Lliga Regionalista, partido de signo conservador que comprendió y apoyó, por haberlo entendido, el programa regenerador del gran político mallorquín.

El Proyecto de 1907 recoge lo más valioso de la tradición local española y significa un intento de conformación del futuro que habría de ir más allá en sus efectos que el Proyecto mismo, pues éste, luego de interminablemente debatido, no llegó a ver la luz como norma legal.

\section{EL MARCO HISTORICO DEL PROYECTO DE REFORMA DE} LA LEGISLACION LOCAL DE 1907

El día 7 de junio de 1907 tiene lugar, en el Congreso de Diputados, la lectura, por el Ministro de la Gobernación, don JUAN DE LA CiERva, del "Proyecto de Ley por el que se establecen las bases para la reforma de la Administración local». El acto tiene lugar ante una Cámara de neto color conservador, donde la mayoría se siente conducida por un líder político indiscutido, que desde el mes de enero ocupa la Presidencia del Consejo de Ministros: don ANToNio MaUra. Junto a la mayoría, escuchan la lectura una parte del partido liberal, las minorías carlista y republicana y un nuevo y heterogéneo bloque regional que bajo el liderazgo de SALMERón agrupaba a fuerzas ideológicas muy diversas: Solidaritat Catalana.

La génesis del nuevo movimiento ha sido exhaustivamente historiada con particular detalle por Jesús PABón y Amadeo HuRTAdo, y aparece conectada con el sesgo político adoptado por el catalanismo desde el comienzo del nuevo siglo. Ya en 1899, La Veu de Catalunya pasa de semanario a diario y adquiere, bajo la dirección de PRAT DE LA RIBA, un nuevo activismo político frente a la línea moderada de La Renaixença. En abril de 1901 nace la «Lliga Regionalista» por fusión del "Centre Nacional Catalá» de los Prats, CAMBÓ, CARner, etc., con la vieja "Unió Regionalista» del capitalismo conservador de los RAVENTós, RoBERT, RusiÑol, etc., y al mes siguiente triunfa la candidatura catalanista (de los cuatro presidentes) en las elecciones legislativas sobre los monárquicos y los republicanos de Pi y de Lerroux. La nueva Lliga forja su experiencia política en su lucha con el lerrouxismo, que le inflige tres severas derrotas electorales a lo largo de 1903. La gran prueba para 
REVL-1974, núm. 181. MARAÑON BARRIO, MIGUEL. LA SOLIDARIDAD ĊATALANA ANTE...

el nuevo partido la constituye, sin embargo, la visita del Rey a Barcelona en 1904.

El ala conservadora era partidaria de aprovechar la presencia del joven monarca para hacerle llegar la protesta y las reivindicaciones catalanistas, en tanto que el sector más liberal, con SuNYoL y CARNER a la cabeza, se mostraba en favor del abstencionismo y la indiferencia, cuando no de una activa hostilidad. El quebrantamiento por Cамвó de este acuerdo, al dirigir un discurso a Alfonso XIII durante la visita de éste al Ayuntamiento, dio origen a una escisión en el seno de la Lliga y al nacimiento de la Esquerra.

El año 1905 asiste a la recuperación de los catalanistas de la serie de desastres vividos en los dos años anteriores, y a lo largo del mismo se producen avances parciales en las elecciones provinciales y legislativas. Particularmente halagüieño fue el resultado de las municipales celebradas en noviembre, en que fueron elegidos doce candidatos de la Lliga para el Ayuntamiento de Barcelona y más de cien concejales catalanistas en todo el Principado. La celebración del éxito en el llamado «Banquete de la Victoria» dio lugar a la publicación de una caricatura, al día siguiente, en el semanario humorístico $\mathrm{Cu}$-Cut, en la que parecía ridiculizarse al Ejército. Interpretada como una provocación, la caricatura motivó una acción de represalia, llevada a cabo por unos trescientos oficiales, en la que resultaron destruidas las redacciones del $\mathrm{Cu}$-Cut y de $\mathrm{La}$ Veu de Catalunya y la imprenta de la primera. Era la noche del 25 de noviembre; cinco días después el Gobierno obtenía de la Cortes la suspensión de garantías constitucionales en Barcelona. Era, como se ha subrayado, el primer acto de la irrupción del Ejército, de forma estamental, en la vida política de España.

En plena situación liberal, la caída de MonTERo Rf́os, el mismo día 30 de noviembre, da paso a un Gobierno MORET, del que forma parte como Ministro de la Guerra el General LuQue, quien, como Capitán General de Sevilla, se había distinguido en su actitud de abierto apoyo a la acción de los oficiales en Barcelona. El nuevo Gobierno presenta y obtiene la aprobación de una Ley de Jurisdicciones, por la que se encomendaba al fuero castrense el conocimiento de los delitos contra la Patria y contra el Ejército. La lucha de los catalanes, dentro y fuera del Parlamento, contra la aprobación dio lugar al nacimiento de la Solidaritat, que integró a la Lliga, la Esquerra, los republicanos de SALMERón, los federales y los tradicionalistas. Sólo los republicanos de LERRoux quedaron fuera de 
esta extensa coalición, que inició su actividad pública por medio de un manifiesto y un mitin en Gerona y la culminó con una multitudinaria manifestación el 20 de mayo de 1906 en Barcelona. El año en el que vio la luz la obra de PraT DE LA RIBA La Nacionalitat Catalana se cerró políticamente en Barcelona con un gran mitin solidario celebrado el 20 de octubre en la plaza de toros de Las Arenas.

Entre tanto, la "situación» liberal agotaba sus últimas posibilidades tras diecinueve meses en el poder y cuatro presidentes del Consejo (Montero Rfos, Moret, LoPez Domf́nguez y VeGa DE ARMIJo). El 25 de enero de 1907 el Rey encomienda a MaURa la formación de un Gobierno conservador. Para el mes de abril se convocaron elecciones legislativas a cuyo copo se lanzó denodadamente la Solidaritat. Como ha escrito Amadeo Hurtado (4), "havia arribat per a Solidaritat Catalana el moment decisiu d'afirmar-se com la formació politica más potent que hagués conegut mai Catalunya».

El resultado electoral, con arreglo a los planes catalanistas y al clima de entusiasmo popular creado por el famoso programa del Tivoli (por el nombre del teatro en que tuvo lugar el mitin correspondiente), no pudo ser más completo. Los adversarios políticos tradicionales, así como el republicanismo centralista de LERROux, sufrieron una derrota aplastante. Solidaritat obtuvo 41 de las 44 actas para el Congreso y todas las del Senado. De un golpe Cataluña colocaba en Madrid, con vocación de pesar en las decisiones políticas, a lo más granado y prometedor de su joven generación política: Sunyol, Puig y Cadafalch, Cambó, Vallés i Ribot, Carner, Hurtado, Ventosa, Rahola, etc.

\section{LA «SOLIDARITAT»Y EL IDEARIO DE MAURA}

Las elecciones de abril, fuera de Cataluña, arrojaron una neta mayoría conservadora, en proporción tal que ofrecía al Consejo una oportunidad única de gobernar con la continuidad y estabilidad requeridas por las importantes medidas que el país demandaba. Comenzaba el mandato del que después habría de llamarse «Gobierno largo», un Ministerio que prometía ser la palanca de

(4) Amadeu Hurtado, Quaranta anys d'advocat, I, Ariel, Barcelona, 1967, página 120. 
las reformas propugnadas por MAURA. En la mente del político balear, la regeneración de España no dependía ya de reformas económicas y sociales de detalle, sino de la superación de las graves deficienciàs políticas que venía evidenciando el sistema constitucional de la Restauración.

Su gran anhelo —en el que coincidía plenamente con el espíritu de los solidarios - era la liberación de las fuerzas vivas del país, la manifestación espontánea de la voluntad popular, de la «opinión» auténtica de la España real, secuestradas ahora por el caciquismo y la oligarquía. Clave de esta práctica política, de la que SAgASTA y ROMERo ROBLEDo habían sido supremos maestros, era la situación de dependencia de los Ayuntamientos respecto de los jefes políticos provinciales y los notables del partido de turno. Por ello era necesario plantear simultáneamente con la reforma electoral la del régimen municipal y provincial, último fundamento de la avergonzante posición de las Corporaciones locales ante las presiones de los caciques. No deja de ser una paradoja que, para llevar a cabo tal política, hubiera sido necesario alcanzar una mayoría parlamentaria por procedimientos tan heterodoxos como los que reprocharon duramente a LA CIERva - Ministro de la Gobernaciónlas minorías liberal y republicana.

En estos propósitos de cimentar el régimen sobre una política de sinceridad electoral -que tantas reticencias parecía encontrar en ciertos sectores conservadores e incluso en Palacio, por sus presuntos resultados antidinásticos en las grandes ciudades- participaba plenamente la Solidaritat. AMADEo HURTADo ha expresado esta afinidad de origen diciendo que aen el pensament de MAURA, com en el nostre, els fets venien a demostrar que aleshores, com sempre, el problema esencial de la vida pública espanyola era constituir el país amb les seves forces naturales en lloc de sacrificar-lo a la constitució d'un Estat»(5). Desde el punto de vista de su actuación parlamentaria, esta afinidad con la mayoría era una perturbadora fuente de ambigüedades para un grupo de oposición como los solidarios. El propio MAURA vino a dar forma a esta íntima contradicción interpelando al grupo catalán: «... creéis encontraros enfrente de lo que abomináis y os encontráis enfrente de la reforma misma... porque aquí tenéis que optar entre una de tres cosas: o habéis de ser una fuerza agitadora, revolucionaria en Cata-

(5) Amadeu Hurtado, op. cit., I, pág. 128. 
REVL-1974, núm. 181. MARAÑON BARRIO, MIGUEL. LA SOLIDARIDAD CATALANA ANTE...

luña, o habéis de ser colaboradores míos, puesto que yo gobierno, o seréis la esterilidad y el fracaso» (6).

El planteamiento del tema regional en el Congreso no se inició, empero, con la discusión del Proyecto de Régimen local, sino con el debate sobre la contestación al mensaje de la Corona. «La restauración de los organismos de Administración local —decía el conceptuoso documento regio- que se os propondrá con voluntad resuelta de abrir amplio cauce para todas las energías que venturosamente brotan de las entrañas del pueblo, y también con el designio de estimular y favorecer la convalecencia de iniciativas enervadas o atrofiadas por una centralización exótica, inadecuada al genio de la nación española, con más la reforma del procedimiento electoral, cuyos vicios frustrarían aquel intento, preliminares son inexcusables para muchas mejoras de los servicios que asume la Administración del Estado"(7). La alusión al centralismo de cuño francés, como ajeno a nuestro genio, tenía que ver con la opinión generalizada, según CARR (8), desde la derrota francesa de 1870, de que los modelos del país vecino estaban en decadencia, mientras que el «self government» anglosajón era más eficaz y estaba, además, más próximo a la tradición autonomista del Municipio castellano.

\section{LA CONTESTACION AL MENSAJE DE LA CORONA}

Al Proyecto de contestación presentaron varios diputados catalanes (Junoy, Bertrán, Milá I Camps, Moles, Llarí, Caballé y lloSAS) una enmienda en la que, amén de pedir el reconocimiento del régimen civil peculiar y solicitar la derogación de la Ley de Jurisdicciones (que "sobre representar en su génesis y aplicación una Ley especial dictada contra determinada región española constituye una regresión absurda en nuestro régimen jurídico»), instaban la inclusión de un párrafo que dio origen a un resonante debate parlamentario.

El párrafo propuesto era del siguiente tenor: «Es preciso vigorizar la vida local y restaurar las energías regionales, reconociendo en las leyes la personalidad de la región y atribuyendo a los orga-

(6) Diario de sesiones del Senado, 1909, págs. 1541 y sigs.

(7) Diario de sesiones del Congreso, 1907, pág. 3.

(8) Raymond CARr, España 1808-1939, Ariel, Barcelona, 1969, pág. 360. 
nismos que la representen muchas de las funciones sociales de enseñanza, beneficencia y obras públicas que indebidamente han venido a ser funciones administrativas directas o delegadas del Estado».

La vaguedad e indeterminación de los términos en que la enmienda se concebía eran ya seguro adelanto de la dureza del debate subsiguiente, sobre todo si se tiene cuenta de las reticencias suscitadas en Madrid por el tono agresivo de la campaña electoral en Barcelona. Ya MaURa había calificado a la Solidaritat de "montón» durante el período de constitución de la misma, y el Presidente electo de la Cámara, Eduardo Dato, recogió su inquietud en el propio discurso de salutación: "Temen algunos que asomen en el horizonte nacional peligros de un regionalismo exagerado, tal vez perturbador, tal vez anárquico. No soy yo de los que abrigan semejantes temores. Seguramente puede asegurarse, para tranquilidad de todos, que el principio más fundamental que la Solidaridad representa, la aspiración más noble de todas las aspiraciones que la Solidaridad abriga, aspiración y sentimientos compartidos por toda la Cámara, son el respeto constante a una Patria única, indivisible, intangible...»

La presencia de 41 diputados solidarios en el Congreso suscitaba el recelo por parte de todos, excepto tal vez del Presidente del Consejo, que supo ver desde el principio la potencia colaboradora de una formación política que había desbancado en toda Cataluña a un mecanismo caciquil, liberal-conservador, tan viejo como la Restauración misma.

Rechazada la enmienda por la Comisión dictaminadora del Proyecto de contestación, el día 12 de junio inician los solidarios la defensa por boca de Amadeo HurTado. Desafortunado discurso, que tuvo la virtud de desagradar a todos: «Pedimos que nuestra propia espiritualidad (regional) no quede subordinada a otras menos perfeccionadas y menos desarrolladas...»; «... nosotros, los que habíamos de venir a este Parlamento como representantes del antipatriotismo, somos los únicos que afirmamos una fe viva, una esperanza decidida en el porvenir de España...»; «... tenéis respecto de nosotros una inferioridad de civilidad, y ésta no se aprende estudiando»(9). La serena respuesta del Ministro de Estado, AllendesalaZAR, tuvo la virtud de poner en evidencia la altivez solidaria. Inter-

(9) Diario de sesiones del Congreso, 1907, págs. 452 y sigs. 
vienen seguidamente por parte catalana Puig y Cadafalch, Sunyol, Ventosa, Junyet y Vallés i Ribot. El tono de los alegatos y de las réplicas ministeriales sufre altibajos, pero marca un signo de desaliento para la minoría catalana, que ve cómo a lo largo del debate van asomando las contradicciones internas, que no han logrado superar su precaria unidad. Regionalistas, carlistas y federales van insensiblemente ahondando en sus discrepancias a la vista de una mayoría conservadora cuyas reacciones, indignadas a veces, son reiteradamente contenidas por MAURA.

Tras la intervención de MACIÁ, que sobrecoge a la Cámara exponiendo sus razones de militar de carrera para integrarse en la Solidaritat, el debate escapa de manos catalanas y se polariza, a un nivel de extraordinaria altura parlamentaria, pero con la consiguiente carga verbalista y retórica, en cuatro oradores de antología: Vázouez de Mella y Salmerón, en favor de la enmienda, y en contra de ella, Melquíades Alvarez y Canalejas.

El discurso de Mella constituye una pieza de primera magnitud por cuanto, tomando como pretexto la enmienda catalana, explaya toda una doctrina tradicionalista sobre las regiones. ¿Es España un agregado de regiones que forman una sola nación o un conjunto de naciones regidas por un solo Estado? La respuesta correcta, para el orador, es la primera proposición alternativa.

El razonamiento de esta opción da pie para una erudita exposición de los factores determinantes de la nacionalidad: raza, geografía, lengua, pasado histórico común, etc. La región -concluyees una sociedad pública, acaso una nación incipiente que, sorprendida en un momento de su desarrollo por una necesidad poderosa que ella no puede satisfacer, se asocia con otras naciones incipientes como ella y les comunica algo de su vida a cambio de lo que de las otras recibe. Junto a los vínculos establecidos por común andadura, persisten, como indelebles rasgos de las respectivas personalidades regionales, la lengua, el derecho y las peculiaridades de orden cultural y organizativo. Frente al centralismo burocratizante, fuente de esclerosis e impotencia, el fomento de la diversidad regional es un fecundo camino de regeneración y vitalidad para la Patria española.

Ya en trance de inevitable retorización del debate, la intervención de SALMERón, a lo largo de dos sesiones, tiene acentos auténticamente sinaíticos (adjetivo que, según PABóN, cuadra más a su oratoria que a la de CASTELAR). Tras de hacer un acto de fe republi- 
cana «irreductible», el anciano ex Presidente de la República lanza un duro alegato a la gestión de los partidos dinásticos desde el desastre. Nada se ha hecho por regenerar el país, por devolverle su representación mundial, porque ésa es obra que no depende de un preámbulo en un decreto ni de unos cuantos preceptos de la ley, sino de la afirmación de las energías sociales que todavía den signos de vitalidad, y la Historia de España prueba que «la tradición no nos ha legado nada vivo, en cuanto a cuerpos de la Nación, más que la existencia de las regiones». La Guerra de la Independencia, el movimiento del año 1820, el de la Junta Central de 1840 ó el levantamiento de 1868 , "¿qué otra cosa son... sino la afirmación vigorosa, sana, fecunda de la existencia de las regiones?» (10).

La discusión ha escapado por entero, a estas alturas, de las manos solidarias. El discurso de Canalejas, del día 20, es un implacable y frío jarro de agua sobre las aspiraciones catalanas. Ataca el concepto, vertido días antes, de la supuesta superioridad de unas regiones sobre otras y habla de su admiración y vinculación a Cataluña, "pero no puedo cantar - dice-, no puedo ahora enaltecer las glorias de Cataluña, porque después de la discusión a que hemos asistido, parecería que intentábamos pagar con la adulación, con un acto de lisonja, frases que, por lo injustas, nos han herido". Analiza luego la petición de autonomía catalana para poner de manifiesto el peligro de una concesión, por mínima que fuese, por parte del Estado, como factor desencadenante de futuras reivindicaciones de imposible satisfacción y, por su misma imposibilidad, generadoras de conflictos y frustraciones. En medio de un tono de suave sarcasmo, pasa después a considerar la otra alternativa: regiones para toda España: "Al lamentaros tanto de las desgracias nacionales, me hacéis algo el efecto de aquel socio opulento, o por lo menos bien acomodado, que en cierto día iba a llorar sus cuitas en la casa del socio pobre». Se dirige luego a SaLMERÓN y le reprocha su vinculación a un pleito tan estrecho como, a su juicio, es el de la Solidaritat: " $i$ Es que podemos contar con vuestro concurso (de los republicanos) ahora o luego?... ¿Es que vamos nosotros a supeditar todos nuestros grandes principios, nuestros ideales, que derivan de principios filosóficos, de aspiraciones humanitarias que apenas se contienen en el límite de la Patria, a la concreción regional?»(11).

(10) Diario de sesiones del Congreso, 1907, págs. 611 y sigs.

(11) Diario de sesiones del Congreso, 1907, págs. 632 y sigs. 
La voz de los republicanos unitarios, humillados por la alianza de su líder natural, SALMERón, con los regionalistas y los carlistas de la Solidaritat, se hizo oír en el debate por boca de Melouíades Alvarez. Toda la capacidad de arrebatado lirismo, toda la fuerza enardecedora de la técnica oratoria del reputado tribuno se dieron cita en esta intervención. Hay primero una dura condenación de la política catalana de los Gobiernos anteriores, que «fue abriendo un abismo entre Cataluña y el Estado español, abismo que ahondaron después los resquemores del amor propio, la procacidad insolente y recíproca de los patrioteros y de los separatistas, la sordidez de ciertos intereses, el orgullo de algunos intelectuales...» En medio de este clima de incomprensión surge la Solidaritat, como una fuerza poderosa, inspirada en un profundo amor a la tierra, que viene a turbar, con aires huracanados, las aguas cenagosas de la política española. En lo que aporta de acicate a los Gobiernos para sacudir su modorra, en lo que supone de purificación del sufragio. el nuevo movimiento significa un bien, y un bien inapreciable. En cuanto a las pretensiones catalanas, propugna desde el mismo momento la abolición de la odiada Ley de Jurisdicciones, no tanto por considerarla un agravic a Cataluña, cuanto por ser la derogación un deber de honor de España con el Ejército y con la libertad de los ciudadanos.

Muy otra es su actitud respecto a la autonomía, que admite de buen grado para los Municipios, pero que niega con vigorosos razonamientos a la región. Si hay regiones en las que existen rasgos de personalidad de los que broten iniciativas encauzables, lógico es otorgarles concesiones como las que el partido conservador ha propuesto en el Proyecto de reforma local. En cuanto a la autonomía demandada por los solidarios, la denuncia como reflejo del fondo de indiferencia y desvío que alienta en Cataluña hacia el resto de España. Califica la propuesta catalana como propia de espíritus mediocres y absolutamente ineficaz, por estrecha y mezquina, para dar a Cataluña la hegemonía sobre la futura España. Defiende a Castilla contra la acusación de haber sido factor de centralización y pone de relieve cómo fue la política imperial de la Casa de Austria la que arrasó primero las libertades municipales de Castilla y Valencia y, por último, las de Cataluña. Niega a Cataluña un papel paralelo al de Prusia o Piamonte en las unificaciones de Alemania e Italia, y respecto al programa autonomista solidario, al no creerlo dotado de la grandeza precisa para constituirse 
en factor de hegemonía, no ve en él sino un vehículo de separatismo o de disolución nacional (12).

El último acto del debate fue el discurso de Maura, previa la intervención de carácter eminentemente técnico-jurídico del republicano Azcárate. El parlamento de MaURa, al margen de la belleza que le halló Azorf́n, tuvo la altura y la responsabilidad propias de un Presidente del Consejo en la plenitud de todos sus recursos. Hace la defensa del Proyecto de contestación como un todo, que por primera vez contiene un programa de gobierno concreto, lejos de las declaraciones corteses y platónicas que solían ser regla inveterada en tales documentos. Se refiere al problema de la enseñanza y al de las Ordenes religiosas para refutar los alegatos extremos de los republicanos y los tradicionalistas.

Finalmente, se encara de lleno con la enmienda solidaria y con la línea seguida por sus defensores a lo largo del debate. Reprocha a los catalanes su jactancia al proclamarse únicos mandatarios auténticos del electorado dentro de la Cámara y puntualiza los logros políticos del partido conservador, al que nadie, en el curso del debate, había hecho la debida justicia. Se refiere a la labor de reconstrucción, subsiguiente al desastre del 98, llevada a cabo por los Gobiernos de Silvela y Villaverde y continuada después, "por la cual está el crédito donde le veis, el interés del dinero tal cual es, el respeto exterior de España como es, todo eso que vosotros olvidáis, sin lo cual sería inútil que se pensara aquí en regiones, ni en autonomía, ni en descentralización, ni en España, porque ya no existiría España».

Se enfrenta más adelante con el tenor literal de la enmienda solidaria, que solicitaba el «reconocimiento en las leyes de la personalidad de la región". "Yo no sé lo que queréis decir con eso de la personalidad. Es más: creo que no lo sabéis vosotros, y, además, creo que no lo queréis decir. Y yo tengo que averiguarlo, porque lo que yo entiendo de eso lo vais a oír ahora. ¿Queréis la personalidad para fines, para jurisdicción, para materia propiamente local? Sin tasa se os reconoce. Vuestra boca es medida. ¿Queréis personalidad para hacer jirones la inconsutil soberanía de la Patria? Nunca; nada. Mientras yo aliente y pueda, jamás logrará un Gobierno sacar una ley que mutile eso".

Adelanta luego juicios sobre el Proyecto de reforma local pre-

(12) Diario de sesiones del Congreso, 1907, págs. 642 y sigs. 
sentado, pero aún no debatido, para recoger las alusiones de que ha sido objeto por diversos oradores y defiende su concepción de la Administración municipal, a la que se encarga totalmente de la gestión de los asuntos locales sin intervención alguna ajena a los elegidos por el vecindario y a los Tribunales de Justicia. Respecto a las objeciones formuladas por VÁzouez de MELla a la doble condición, local y central, de los Alcaldes, la refuta en base a la imposibilidad de un Estado que tenga su clientela "en la vía láctea», porque no hay nada en España que no sean Municipios o vecinos, so pena de que el Estado extienda su jerarquía administrativa hasta el último rincón del país nombrando 400.000 ó 500.000 empleados de una vez. El carácter de agente delegado del poder central de que se inviste al Alcalde no empece a la idea de descuaje del caciquismo, ya que, como tal autoridad, limita su actuación al campo del orden público, sin que le correspondan facultades propias en orden a la Administración municipal.

En relación con el tratamiento de las regiones, el Proyecto no da la posibilidad al poder central de crear por decreto la región catalana ni ninguna otra - -so sería una nueva y sutil forma de centralismo jacobino-, sino que se limita a trazar, por vía de las Mancomunidades, el marco jurídico para que la libre voluntad provincial pueda establecerlas (13).

El debate llegaba con ello a su fin. Aún habría de dar unos últimos coletazos polémicos, pero las actitudes de las diversas minorías y del Gobierno quedaban ya definitivamente encauzadas para la discusión del Proyecto, que había de iniciarse con la reanudación de la actividad parlamentaria tras el paréntesis veraniego. Ossorio y Gallardo, Gobernador civil de Barcelona, escribe a MAURA sobre las consecuencias del debate: «El efecto que ha causado en los solidarios ha sido como el de un garrotazo en la cabeza..., al ver que es posible negarles resueltamente su maliciosa pretensión de personalidad regional, sin herirles ni mortificarles y sin regatearles sus ambicionadas libertades administrativas»(14).

(13) Diario de sesiones del Congreso, 1907, págs. 659 y sigs.

(14) Jesús Pabón, Cambó, I, Edit. Alpha, Barcelona, 1952, pág. 300. 


\section{LA CRISIS INTERNA DE LA SOLIDARIDAD}

El primer acto de presencia de los diputados catalanes en la Cámara no había arrojado, sin embargo, un saldo negativo. Por boca de sus más moderados representantes habían manifestado su voluntad de colaborar con la obra del Gobierno, aun haciendo expresa declaración de desencanto por el Proyecto de reforma local, que no estimaban instrumento adecuado para dar satisfacción a sus reivindicaciones. Los parlamentarios de la Solidaritat respondieron con creces a la expectación con que se les recibió en Madrid y aportaron a los debates una cultura y una visión moderna de las realidades patrias que impresionaron por lo que tenían de contraste con la oratoria grandilocuente al uso. Algunos de sus hombres, como Puig y Cadafalch, Sunyol y Ventosa, fueron oídos en respetuoso silencio incluso cuando sus afirmaciones sobre el régimen, la inoperancia de los Gobiernos o el dudoso carácter representativo de los diputados suscitaron las irritadas reacciones de la mayoria conservadora, reiteradamente contenida por el gesto autoritario de MAURA. Tal vez su error primordial, junto a la ingenuidad de ciertos planteamientos y una determinada incontinencia en la agresividad interpeladora, fue encomendar la jefatura del grupo al anciano y pasional SALMERón.

Por lo demás, el transcurso de la discusión fue haciendo más patentes las discrepancias internas lógicas en unos hombres que procedían de credos políticos tan diferentes e incluso opuestos. En efecto, el contexto político de la época tenía puestos sobre el tapete temas especialmente polémicos, que inevitablemente hubieron de salir a colación en un debate de tan amplia participación: el problema de la pureza del sufragio, la cuestión religiosa, la discusión sobre el régimen y la dinastía. Por tales resquicios se fue infiltrando la discrepancia entre los monárquicos, los carlistas, los republicanos y los federales que, además de los regionalistas de la Lliga, militaban en las filas solidarias.

El espíritu popular que había inspirado la Solidaritat estaba, sin embargo, absolutamente vivo en Cataluña, que había comprendido la posibilidad real del grupo solidario de construir en las Cortes un factor importante de transformación en la política española. Desde la Presidencia de la Diputación de Barcelona, PRAT DE LA RIBA se entregaba a una labor de modernización de los servicios 
utilizando el entusiasmo y las capacidades técnicas de la región y comunicando a muchos, según HURTADo, la convicción de que una simple Mancomunidad podría transformar la Administración catalana, para lo que había de sobra con sólo dos instrumentos: «un llibre d'actes i un segell" (15). Cataluña abrigaba la convicción de que le correspondía un papel primordial en la formación cívica del resto de las regiones de España.

Todo el espíritu de los tiempos en la región estaba compendiado en la obra de PRAT DE LA RIBA, La Nacionalitat Catalana, y éste era el slogan de los solidarios cuando entraban en contacto con sus electores: «Redimir tota Espanya anb l'exemple y la força de Catalunya». Sin embargo, la coincidencia de fondo de esta actitud política con la nueva línea nacional de MAURA no era compartida unánimemente por todos los solidarios, y esta diferencia interna había de manifestarse en forma ostensible y clara con motivo del Proyecto de reforma de la Administración local. Así, mientras los hombres de la Lliga - PrAT en Barcelona, y CAMBÓ, "la voluntat de Catalunya en acció", en Madrid- defendieron el Proyecto en todo lo que tenía de aprovechable, la izquierda solidaria se empeñaba en combatirlo por el simple hecho de su procedencia (16).

Ya en el mes de junio, durante el debate del Proyecto de contestación a la Corona, PRAT DE LA RIBA, que se había trasladado por unos días a Madrid, escribe una carta en la que da cuenta del nerviosismo que reina entre los diputados catalanes en aquellas jornadas. En ella, después de destacar su admiración por la réplica de Puig y Cadafalch a los demoledores discursos de Melouíades Alvarez y de Maura en el Parlamento, hace una alusión irónica a la inhibición de los hombres de la Esquerra en el momento en que se abatía sobre el grupo catalán el grueso de la artillería oratoria del adversario» (17).

Durante el verano no cesa la actividad preparatoria con vistas a la reapertura de las Cortes. CАMBÓ convalecía de las heridas recibidas en el atentado de Hostafranchs - del que salió ileso SALMERÓN, al que acompañaba durante la campaña electoral- (18), pero pudo realizar un estudio del Proyecto, que comparó con el

(15) Hurtavo, op. cit., pág. 136.

(16) Olivar Bertrand, Prat de la Riba, Barcelona, 1964, págs. 194 y sigs.

(17) Olivar BERTRAND, op. cit., pág. 412.

(18) Pueden verse los detalles del famoso atentado, del que se acusó a los lerrouxistas, en PABON, op. cit., I, págs. 278 y sigs., donde se hace el puntual relato de la campaña electoral de la Solidaritat. 
realizado separadamente por SunYol, y del que resultó una coincidencia notable de puntos de vista. Sin embargo, las rivalidades internas de la Solidaritat asoman, por encima de estas coincidencias, en el tono agresivo de El Poble Catalá, órgano de la Esquerra, que contrasta con los términos más mesurados y corteses que emplea La Veu de Catalunya, portavoz periodístico de la Lliga.

Con la discusión parlamentaria del Proyecto de reforma de la Administración local, iniciada el 14 de octubre de 1907, se consuma la disgregación de la Solidaritat. PABÓN ha dejado puntual y clara reseña de los hechos (19) y a su relato resulta forzoso remitirse. Cuatro hitos fundamentales jalonaron la crisis solidaria: $10^{\circ} \mathrm{La}$ cuestión personal, seguida de su retirada, suscitada por SunYol, al ver concentrarse el liderazgo de la minoría catalana en manos de la Lliga. 2. La campaña de El Poble Catalá, encaminada a denunciar la presunta colisión de la Lliga con MAURA, para defraudar las auténticas aspiraciones catalanas. $3 .^{\circ}$ La cuestión del voto corporativo en la esfera municipal y las elecciones de segundo grado en la provincial, previstas en el Proyecto, que eran admitidas por la Lliga y rechazadas por la Esquerra y los republicanos. $4 .^{\circ}$ La exigencia del ala izquierda de la Solidaritat para que MAURA derogase la Ley de Jurisdicciones «inmediatamente». La muerte de SALMERón, conservador de la concordia solidaria a todo trance, vino a consagrar con carácter definitivo un divorcio virtual que se venía arrastrando casi desde el principio.

\section{EL PROYECTO DE 1907: SUS CARACTERISTICAS Y AVATARES}

Como ha escrito Amadeo Hurtado, el Proyecto de reforma de la Administración local estaba destinado a ser el trabajo más importante de la legislatura y había de hacer de Cataluña y de sus hombres el tema permanente de la actualidad parlamentaria. Renunciando a la forma de Ley de Bases, intentada en 1903 por MAURA, el Proyecto ahora presentado tenía una estructura perfectamente articulada (20), aunque la filosofía que lo inspiraba emanaba claramente de la contenida en las 24 bases de 1903.

(19) PABÓN, op. cit., I, págs. 304 y sigs.

(20) El Pruyecto se encabeza con un artículo único del siguiente tenor: ${ }_{\alpha}$ Se autoriza al Gobierno para publicar y aprobar como Ley el adjunto Proyecto sobre Régimen de la Administración local». A continuación venía el texto completo, integrado por 400 artículos y cuatro disposiciones adicionales. 
Formalmente, el Proyecto se ofreció a los diputados impreso en forma de libro, con márgenes de una anchura de media plana para las anotaciones y enmiendas, lo que, a juicio de Hurtado (21), mostraba el interés de MAURA de dar las máximas facilidades a las Cámaras para colaborar en la discusión en la forma más amplia y completa posible. Este tipo de "colaboración» no había de faltarle ciertamente al Gobierno. En efecto, entre las presentadas por el Congreso y por el Senado, el número de enmiendas al Proyecto alcanzó la cifra de 2.813 , y en la discusión del mismo, en una y otra Cámara, se pronunciaron 5.511 discursos (22). Como ha escrito ANTonro CARro (23): «Ha sido ésta quizá la más patente muestra de impotencia parlamentaria que registra la historia de las modernas Cortes Españolas». Desde el 14 de octubre de 1907 hasta julio de 1909 se extendió un debate penosísimo, al final del cual no se había aprobado ni la mitad del Proyecto, lo que hubiera arrojado posiblemente un "record" maratoniano en la historia parlamentaria mundial de no haberse visto interrumpido por la grave crisis política provocada por la Semana Trágica de Barcelona.

Los cometidos fundamentales de la reforma, el «descuaje» del caciquismo y la autonomía local se apoyaban, según Posada (24), en ocho enunciados básicos: 1. Integración ordenada, según prin. cipios jurídicos generales, de todo el régimen local (municipal y provincial). $2 .^{\circ}$ Reconstrucción de los pequeños Municipios en las Mancomunidades y de la administración de aldeas, barrios y caseríos. 3..$^{\circ}$ Organización de las Mancomunidades legales y voluntarias en la esfera municipal. $4 .^{\circ}$ Establecimiento de la representación corporativa junto al cauce del sufragio inorgánico. 5. Supresión del carácter de organismo permanente de los Ayuntamientos y creación de la Comisión Municipal. 6. Reorganización del régimen jurídico de los acuerdos de los Ayuntamientos y de los recursos respecto de los mismos. $7 .^{\circ}$ Régimen de tutela de las Corporaciones locales. 8..$^{\circ}$ Modificación de la composición de las Diputaciones y posibilidad de mancomunarse entre ellas.

Sobre la mayoría de estos enunciados, que alcanzarian en buena parte el Boletín Oficial, gracias a Calvo Sotelo, sólo tres lus-

(21) $O p$. cit., I, págs. 135 y sigs.

(22) PABON, op. cit., I, pág. 304.

(23) A. Carro Martinez, "Génesis y trayectoria de las reformas locales de Mauran, en Ideario de don Antonio Maura sobre la vida local, I. E. A. L., Madrid, 1954, pág. 312.

(24) En PABÓN, op. cit., I, pág. 302. 
tros más tarde, no vale la pena insistir para los efectos de este estudio. El interés esencial del mismo se centra en torno a la figura jurídica de la Mancomunidad provincial, que polarizó las más intensas discusiones por lo que tenía de consagración, en forma asaz tímida para algunos, de la idea regional en nuestro Derecho local.

Nombrada la Comisión dictaminadora, presidida por SÁNCHEZ GuERRA (25), el 3 de julio dio por terminado su trabajo. El comienzo del debate en el Congreso tiene lugar el 14 de octubre, y el primer turno sobre la totalidad lo consume el líder de los liberales, don SEgISMUNdo MoRET. En paradójica contradicción con la incesante labor obstruccionista llevada a cabo a lo largo de las interminables discusiones, esta primera intervención del jefe liberal se inicia con un canto de alabanza a la oportunidad y aun necesidad del Proyecto. Por lo demás, el tono del discurso planeó en las alturas políticas y sólo descendió para criticar el procedimiento para la designación de Alcaldes y las modificaciones introducidas por la Comisión dictaminadora en la disposición adicional tercera, en que se preveía la posibilidad de las Mancomunidades provinciales. Estima que en dicha disposición aparece una reforma, de carácter casi constitucional, que es «la más considerable que se puede presentar a las Cámaras de una Nación» y que, además, la Comisión ha introducido en ella elementos que la sacan de su primitivo molde llevando sus condiciones a extremos hasta donde en principio no llegó el Proyecto del Gobierno (26). Termina su alegato interpe-

(25) Formaban la Comisión con Sánchez Guerra (conservador), el Secretario, Carlos Cañal y Migoya (conservador) y los siguientes vocales: Abilio Calderón Rojo (conservador), José Bellver Oña (maurista), Luis Maldonado y Fernández Ocampos (conservador), Antonio Marín de la Bárcena (maurista) y José Lombardero Franco (conservador). Es de destacar la circunstancia de que don José Sánchez Guerra había sido Ministro de la Gobernación en los gobiernos conservadores de 1903 y 1904. (Modesto SáNCHEZ DE LOS SANTOS, Las Cortes Españolas. Las de 1907.)

(26) A efectos de la debida comparación he aquí reproducidos ambos textos. Decía el Proyecto del Gobierno: Disposición adicional tercera: "Los Ayuntamientos, las Diputaciones y las Mancomunidades que los unos y las otras formen voluntariamente podrán solicitar, y con el beneplácito del Gobierno obtener, por vía de concesión o de contrato, siempre dentro de la observancia de las leyes vigentes para cada materia administrativa, los servicios y las obras públicas que interesen a la región, la comarca o el territorio respectivos, aunque los tales servicios o las tales obras no estén comprendidos en la competencia exclusiva que se asigna a las Corporaciones locales. Las concesiones o contratos, según las cláusulas o condiciones respectivas, regirán las relaciones entre el Gobierno y la entidad que asumiere obras o servicios de la Administración central, con entera separación de las facultades propias, que en asuntos locales están atribuidas a dichas Corporaciones».

Por su parte, el texto de dicha disposición elaborado por la Comisión decía así: «La formación de Mancomunidades para fines de índole local en esta Ley asigna- 


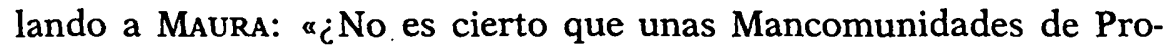
vincias, aprobadas por el Gobierno... serían verdaderas federaciones en las cuales se repartiría el territorio y la acción de la nacionalidad española?»

Esta forma de apertura determinó la inclinación del debate hacia la problemática regional, lo que dio lugar al replanteamiento de las cuestiones ya suscitadas con ocasión de discutirse la contestación al mensaje del Trono. Tan fue así, que a los tres turnos previstos para la totalidad hubo que añadir, por acuerdo del Congreso del día 19, seis turnos más, consumidos en contra cinco de ellos

dos, ora a la competencia municipal, ora a la provincial, podrá ser iniciada: 1) por el Gobernador; 2) por alguna de las Corporaciones interesadas en el Proyecto; 3) por la mayoría de diputados a Cortes, juntamente con los senadores, en cuyas elecciones hayan tenido parte pueblos o Provincias comprendidos de algún modo en dicho Proyecto.

Este deberá expresar siempre: 1) los fines determinados de la Mancomunidad, reconocidos por esta Ley como propios de la Administración local; 2) los Municipios o las Provincias a quienes se intente mancomunar; 3) los recursos en que haya de consistir la hacienda de la Mancomunidad, y 4) si ésta ha de durar indefinidamente, un tiempo fijo o mientras se alcance determinado objeto.

El Proyecto deberá ser en todo caso comunicado a las Corporaciones locales interesadas, las cuales sobre él deliberarán en pleno y acordarán y expondrán lo que estimen conveniente. A la vez nombrará cada una de dichas Corporaciones mandatario suyo, sujeto a los acuerdos de ella, para una asamblea cuyas deliberaciones requerirán asistencia de los enviados de las cuatro quintas partes de las Corporaciones que el Proyecto comprenda. El acuerdo de la asamblea favorable a la formación de Mancomunidad no será obligatorio para todas ellas sino cuando tenga los votos de dos terceras partes del número de Corporaciones $\mathrm{y}$, además, los habitantes representados por las Corporaciones adheridas excedan a los dos tercios de la población total, según el censo de la comarca designada para la Mancomunidad en proyecto.

Iguales requisitos serán inexcusables para cualesquiera acuerdos de asamblea sobre adopción o alteración de estatutos o reglas para el ordenamiento de la Mancomunidad, una vez que haya prevalecido la determinación de formarla.

La convocatoria y presidencia de la asamblea, así como la comunicación del Proyecto a Corporaciones que separadamente hayan de deliberar sobre él y nombrar mandatario, incumbirá al Gobernador de la Provincia cuando se trate de mancomunar tan sólo Municipios de ella; mas cuando el Proyecto abarque Corporaciones de dos o más Provincias, corresponderá al Ministro de la Gobernación o al Gobernador de alguna de éstas, encargado por él.

Las Mancomunidades así formadas tendrán plena capacidad jurídica para los respectivos fines expresos. Además, los Ayuntamientos, las Diputaciones y las Mancomunidades que los unos y las otras formen voluntariamente podrán solicitar, y con beneplácito del Gobierno obtener, por vía de concesión o de contrato, siempre dentro de la observancia de las leyes vigentes para cada materia administrativa, los servicios o las obras públicas que interesen a la región, la comarca o el territorio respectivos, aunque los tales servicios o las tales obras no estén comprendidos en la competencia exclusiva que se asigna a las Corporaciones locales.

Estas concesiones o contratos, según las cláusulas o condiciones respectivas, regirán las relaciones entre el Gobierno y la entidad que asumiere obras o servicios de la Administración central, con entera separación de las facultades propias, que en asuntos locales están atribuidas a dichas Corporaciones». 
por diputados catalanes. El debate alcanzó así notable importancia y requiere por ello una descripción particularizada.

Contestó la Comisión por boca de don José SÁnCHez GuerR.4, que defendió su postura invocando contra los alegatos de MORET el precedente del Proyecto presentado por él mismo en 1884, siendo Ministro de la Gobernación, por el que se dividía el territorio español en trece regiones - una de ellas, con capitalidad en Barcelona, integrada por Barcelona, Lérida, Tarragona y Gerona-, al frente de las cuales habría una Diputación regional. A esta contradicción básica del líder liberal, agregó la larga trayectoria doctrinal del mismo en favor de la descentralización, palabra que ahora le asustaba cuando pretendía consagrarse en la legalidad, por vía de los contratos o concesiones del Gobierno a las Provincias mancomunadas en materias ajenas a la competencia local. Tercia MAURA en el debate, y para conciliar posturas, sólo en apariencia contradictorias, pronuncia un discurso el día 15 de octubre, en el que explaya su filosofía y la del partido conservador acerca de las relaciones del poder central con los entes locales. Como reconoce el propio MORET en su rectificación, la marginal exposición del Presidente del Consejo de Ministros ha venido a ser el preámbulo que se echaba de menos en el Proyecto.

El segundo turno en contra lo consume el diputado de la Lliga BERTRÁ Y MUSITU, permaneciendo deliberadamente fuera de la temática regional y concentrándose en los temas que habrían de ser en lo sucesivo caballos de batalla de la discusión: nombramiento de los Alcaldes, doble carácter de éstos, tutela del Gobierno sobre los Ayuntamientos, insuficiencias financieras de los mismos, etc. Le contesta por la Comisión Maldonado, y tras un nuevo turno en contra, a cargo del carlista Díez Aguado y SAlABerRi, a quien contesta BELlVER, se acuerda por la Cámara ampliar en seis más el número de turnos de discusión dada la importancia excepcional del Proyecto.

El primero de ellos lo consume el diputado solidario ILDEFonso SUNYOL, líder de la facción nacionalista del grupo catalán. En opinión de HuRTADo, «el seu eloqüent discurs... era realment una lliçó de dret administratiu, d'una critica implacable contra el projecte del Gobern» (27). Para el estudioso, la lectura de este discurso constituye un oasis de sencillez y precisión en medio del desierto ora-

(27) Hurtado, op. cit., I, pág. 137. 
torio de los días anteriores, lleno de ampulosidad tonante, plagado de interjecciones e invocaciones, quejumbroso y, a veces, irresponsablemente frívolo. Toda la Cámara queda fuertemente impresionada. El MARQués dE LA Vega de ARmijo, último Presidente de la anterior etapa liberal, exclama: «iQue vengan los criados a barrer el Proyecto, que está aquí hecho pedazos en el suelo!»(28).

Empezó SunYol por aludir a las esperanzas que en todas partes, sobre todo en Cataluña, despertó el solo anuncio de la reforma de la vida local que se proponía MAURA, y de la inmediata decepción producida por el Proyecto. Acusa a los conservadores de haber incurrido en el defecto de siempre: creer en la eficacia y virtualidad de la leyes y apartar la mirada de la realidad viva y fecunda. Y en esta realidad, con mayor autenticidad que las 49 Provincias, de cuya artificiosidad todo el mundo se ha venido quejando desde la misma fecha de su creación, se encuentra a Cataluña, a Aragón, a Galicia, a Andalucía, etc. No extrañaría eso al orador si el Proyecto se debiese a un Gobierno liberal y doctrinario, pero le sorprende en un Gobierno presidido por MAURA, en quien las clases conservadoras habían puesto la esperanza de que iba a traer un conservadurismo político a la inglesa, con un sentido de la realidad incapaz de desconocer la existencia histórica de las regiones, que tienen en España los caracteres de auténticas nacionalidades. Critica la vía hacia la región que propone el Gobierno por estimar hipócrita la solución de las Mancomunidades. "Si vosotros creéis en la existencia de la's regiones, tenéis el deber ineludible de consignarlas en la ley; y si no creéis en ellas, tenéis el deber ineludible también de no permitir que por una manera indirecta se vaya a la creación de organismos completamente arbitrarios. ¡Existen organismos vivos y los queréis crear artificiales! Tenéis un hombre de carne y lo queréis hacer de madera".

El resto del discurso pasa revista a los temas más candentes de la regulación de la vida municipal. La eficacia de sus alegatos, cortos, rápidos, despojados de toda hojarasca retórica, se hace patente entre los diputados. "Habéis anunciado una revolución y lo que habéis hecho es un simple cambio de postura...; dejáis a España dividida artificialmente en 49 Provincias, que vosotros mismos decís que no tienen realidad en la vida... Todo quedará de la misma manera: el Estado, centralista, como hasta aho-

(28) Hurtado, op. cit., I, pág. 137. 
ra; el Ministro de la Gobernación, regulando y siendo el amo, señor y dueño absoluto de la vida local del país... No habéis resuelto el problema regional...; no habéis resuelto el problema catalán...» Manifiesta haber leído proyectos, artículos y discursos de Silvela, de Maura, de Sánchez Guerra, de Sánchez de Toca. «Todos son autonomistas y, sin embargo, todos pasan por el Gobierno y la autonomía no aparece por ninguna parte» (29).

Por la Comisión contesta a Sunyol, AbIlio Calderón. Intervienen luego en contra, por parte de la Solidaritat, JUNOY (republica. no) y Pi y Arsuaga (federal), contestando por la Comisión CaÑal y Lombardero. El 25 de octubre interviene, para consumir el séptimo turno en contra, el diputado de la Lliga Francisco Cambó. Viene avalado por la aureola trágica del atentado de Hostafranchs, y su presencia suscita inusitado interés y gran expectación en el Congreso. Frente a la actitud pesimista de Sunyol, Самвó da signos de voluntad dialogante con el Gobierno, sin dejar por ello de hacer una crítica ponderada del Proyecto. Mientras a unos periódicos ha inquietado su crudo catalanismo, a otros, como El Mundo, les parece САмвठ́ «un maurista más». El discurso hubo de ser dividido y llegó a su remate el día 26. La impresión generalizada daba a CAMBó el carácter de líder del grupo catalán, y $A B C$ refleja así esta impresión: "Habló por primera vez СамBó, el Maura de los solidarios» (30).

Este sesgo político de la actuación de Cамвó determinó un serio y primer deterioro de la cohesión solidaria. Celoso Sunyol del liderazgo tácito de los hombres de la Lliga, un suceso, trivial según PABÓN, vino a hacérselo intolerable. Terminado el discurso de CAMBó contestaron SÁNChez GuERRA y el propio MaURa. Rectificó САмBठ́, y la tensión provocada por su discurso se volcó acto seguido por los pasillos del Congreso, por lo que Sunyol se vio en la necesidad de hablar ante una Cámara semivacía. La reacción, que PABón califica de enfermiza, consistió en estimar que la voz de los nacionalistas republicanos, es decir, de la Esquerra, no tenía valor alguno para el Gobierno, por lo que procedía la retirada (31).

Para Hurtado, los hechos tienen otra interpretación. El diálogo entablado por MAURA y CAMBó con motivo de sus mutuas rectificaciones atenuaba progresivamente la rigidez de las posiciones res-

(29) Diario de sesiones del Congreso, 1907, págs. 1930 y sigs.

(30) PABÓN, op. cit., I, págs. 305 y sigs.

(31) Op. cit., I, págs. $300 \mathrm{y}$ sigs. 
pectivas, lo que, unido a la simpatía y deseo de colaboración mostrados por MAURA hacia el joven diputado catalán, venía a reforzar la autoridad de éste ante la mayoría conservadora. Y concluye terminantemente HURTADo: «Tot hom havia vist clar el proposit de MAURA i de la majoria conservadora, de governar en els afers de Catalunya, cada día más influents en els afers generals d'Espanya, d'acord amb la Lliga, que era el nostre partit conservador" (32).

Con estas reticencias y la creencia de que la Lliga aspiraba a convertirse en partido único dentro de Cataluña, se inició la crisis interna de la Solidaritat de que antes hemos hecho mención. La crítica histórica posterior ha puesto de manifiesto hasta qué punto las aspiraciones de la Lliga eran las de las clases conservadoras catalanas, deseosas de una libertad fundamentalmente cultural y económica para convertir a Cataluña en el centro hegemónico de España. En el seno de la Solidaridad chocaban con los republicanos en cuestión del régimen, con los carlistas en el tema dinástico y con los nacionalistas (CARNer, SunYol, etc.) en la moderación de sus aspiraciones regionales. La derrota solidaria en las elecciones parciales a que dio lugar la muerte de SALMERón en 1908 (y que dieron el triunfo en Barcelona a SOL y ORTEGA, LeRroux y GiNer DE LOS Rfos) acabó con los últimos vínculos solidarios.

Pero no adelantemos acontecimientos y volvamos al hilo del debate. La contestación de SÁNCHEZ GuerRa al discurso de CAmbó tiene carácter de controversia histórica. Todo el hábito dialogante del parlamentario consumado, toda la capacidad de discutir sin romper lazos, asoma en este habilidoso discurso. Invita a los catalanes a prescindir de maximalismos y audacias verbales a los que sólo la disciplina impuesta por MaURa impide que respondan en igual tono los diputados de la mayoría. Y defiende la disposición adicional tercera del Proyecto, tan atacada por los solidarios, sobre todo los partidarios del "tot o res», diciendo: « $i$ Es tan vivo ese sentimiento regional en Cataluña; es tan grande, como el señor CAMBó declara, esa aspiración que ha proporcionado este triunfo - se refiere al triunfo electoral - a la Solidaridad catalana? Pues si ahí está la necesidad, ahí está el cauce; llenadlo» (33).

Un incidente parlamentario, motivado por las alusiones personales, suscitó una durísima polémica entre los catalanistas y el par-

(32) Op. cit., I, pág. 138.

(33) Diario de sesiones del Congreso, 1907, págs. 2096 y sigs. 
tido liberal, en particular el diputado BuRRELl. Todas las cuestiones soterradas, que venían cerniéndose amenazadoramente sobre el dèbate desde su inicio, salieron apasionadamente a relucir. El separatismo, el amor a la Patria española, las campañas de prensa que, desde Madrid y Barcelona, envenenaban los ánimos de concordancia y entendimiento, asomaron con toda su carga perturbadora. Ello hizo precisa la intervención de MaURa, que con su discurso del día 29 de octubre vino a tornar las aguas del debate a su cauce parlamentario propio. Su acercamiento а САмвб dio lugar al incidente que motivó la retirada de SunYol, decepcionado por el giro de los acontecimientos.

Consume el octavo turno el republicano Jimeno RoDRIgo, al que contesta Maldonado por la Comisión, y el noveno, Vallés I RIBot, solidario federal, contestado por Lombardero. El debate se torna ahora reiterativo y machacón, pero no termina. Las intervenciones para alusiones personales dan entrada a Azć́rate y al Ministro de la Gobernación. Se remonta de nuevo el tono de la discusión y alcanza elevadas cotas los días 6 y 7 de noviembre con la actuación de Canalejas.

El discurso del líder demócrata tiene mucho de paradigmático, en cuanto contiene una versión del problema catalán bastante típica de la mentalidad centralista. Traza la distinción entre "programa mínimo" y "programa máximo" en las reivindicaciones catalanistas, y aunque no duda del patriotismo de los solidarios, sí desconfía del extremismo maximalista de la extrema izquierda catalana, cuya presión desde Barcelona sobre sus diputados es ostensible. Habla de la prosperidad económica y cultural de Cataluña y pone de manifiesto cómo ha sido posible dentro de un sistema centralista como el que continuamente reprochan al Estado. La prosperidad presente y futura de Cataluña ha de ir inexorablemente asociada a la de España, en una obra de solidaridad nacional, "de suerte que cuando basáis vuestras predicaciones en una economía catalana... sufrís el espejismo, la atracción seductora, pero peligrosa, de grandes bienes y riquezas, de pródigos desarrollos de una economía local, olvidando que para eso necesitáis el apoyo vigoroso de una gran economía de la Nación entera».

Critica la aspiración catalana de perpetuar las singularidades de su Derecho tradicional, que se encuentra en pugna con la corriente universal hacia una homogeneización, por encima de las fronteras, de las instituciones propias de cada rama del Derecho. La 
vaguedad con que se regulan en el Proyecto las Mancomunidades provinciales le despierta fuertes temores, pues esta misma indeterminación hace que asomen, dentro y, sobre todo, fuera de la Cámara, opiniones que sustentan la idea de una personalidad política para las regiones. «... A que haya dos Naciones, una que se llame Cataluña y otra que se llame España, a eso no voy, ni para discutirlo siquiera» (34).

Zarandeado el Proyecto desde extremos opuestos, reprochándole los federales y solidarios su timidez e ineficacia para un verdadero saneamiento de la vida local y desconfiando los liberales y unionistas ya de su escaso espíritu democrático, ya de su potencial carácter de vehículo de separatismòs futuros, se ve MAURA en la necesidad de intervenir nuevamente en el debate para puntualizar el alcance y la intención de una reforma que todos reclaman, porque nadie se ha mostrado ni puede mostrarse partidario del statu quo. Invita Maura a todos a participar en la mejora de un Proyecto, que el Gobierno sabe perfectible, y reclama la colaboración necesaria para dar respuesta a los apremiantes requerimientos del país, para lo que está dispuesto a dar, desde el principio, toda clase de facilidades.

Aún han de intervenir, para las rectificaciones, MORET, CAMBó y Canalejas, pero el debate no hace ya sino martillear sobre los mismos temas. Nada bueno puede salir de él para el futuro del Proyecto. Frente a la facilidad y brevedad con que se aprobó, aun antes del verano, la Ley Electoral, este Proyecto habrá de enfrentarse con una decidida obstrucción por parte de los liberales y de los republicanos.

Consciente MaURa de la lentitud que el proceso parlamentario normal imprimiría a la aprobación del articulado del Proyecto, decidió sacar a éste del salón de sesiones para llevarlo a una sección del Congreso. Allí fue discutido en petit comité por miembros del Gobierno y de la Comisión dictaminadora, así como por aquellos diputados más interesados en él. Las enmiendas solidarias, redactadas por una ponencia integrada por Salmerón, CAMBo, Vallés I Ribot, Carner, Hurtado y Alier, fueron presentadas en esta sección del Congreso - conocida por «el cine»- por CARNER y CAMBÓ, designados a tal efecto por la Solidaritat. La enfermedad de un

(34) Diario de sesiones del Congreso, 1907, págs. 2298 y sigs. 
pariente del primero dejó solo a Самвó, y su intensivo trabajo dio como resultado la modificación de 260 de los 400 artículos del Proyecto.

\section{HACIA UN HORIZONTE REVOLUCIONARIO}

La personal actuación de CамBó en los trabajos de reelaboración del Proyecto de Régimen local y el brillante resultado de la misma a lo largo de 1908 vino a ensombrecer aún más las relaciones internas de los solidarios catalanes. La izquierda habia organizado por su cuenta, en Cataluña, una campaña contra el voto corporativo previsto en el Proyecto y acordó luego una actitud parlamentaria de sistemática obstrucción al mismo.

Al borde de la vacación estival de 1908, los diputados catalanes de la Esquerra presentan una proposición solicitando de la Cámara la derogación de la Ley de Jurisdicciones - leit motiv del movimiento solidario de 1906- «inmediatamente». Se opone MAURA a tan perentoria petición, y, pese a los esfuerzos conciliatorios de la Lliga, acordó el grupo de la Esquerra retirarse del Parlamento. Un último esfuerzo de Durán y Ventosa, apoyado por Prat de la Riba, logró el regreso a las Cortes de los disidentes. Pero la diáspora era ya irremediable y acabó por consumarse definitivamente con la muerte de SALMERón, el 20 de septiembre del mismo año. El resultado fue la doble derrota en las elecciones parciales a Cortes a finales de 1908 y en las municipales de 1909. LERroux volvía a erigirse en árbitro de la política en Cataluña (35).

El debate sobre la reforma local arrastra su penosa marcha, abriéndose camino a través de la obstrucción de las minorías de la oposición en el Congreso y en el Senado. Pero el gran peligro para las aspiraciones catalanas, dependientes de la vitalidad del Gobierno MAURA, vendrá por un camino mucho más brutal e inesperado: la huelga revolucionaria que estalla el 26 de julio en Barcelona y que dará lugar a los dramáticos sucesos de la Semana Trágica.

Todo el desgaste de la situación conservadora, a lo largo de la represión, el juicio y ejecución de FERRER y la algarabía internacional de que se hizo eco el partido liberal en España, desembocan en la caída de MaURA, en octubre de 1909. El catalanismo vive las

(35) РАвல́, op. cit., I, págs. 318 y sigs. 
tristes horas del desencanto luego de la euforia solidaria de 1906. La llegada de Moret al poder equivale al derrumbe de todas las esperanzas que había alimentado el sentido regenerador del «Ministerio largo».

La lucha por la autonomía habría aún de seguir un largo y accidentado camino hasta 1932, pasando por los proyectos de CANALEJAS, el Real Decreto de Mancomunidades de DATo, la nueva campaña frente al Gobierno Romanones y el paréntesis de la Dictadura. Pero ésa es ya otra historia. El campo cronológico de este estudio se detiene justamente en el punto en que el intento del catalanismo como ensayo regenerador, luego de conocer una dorada oportunidad histórica a la sombra de la figura gigante de MaURA, se hunde en el fracaso.

Para el espectador de nuestros días queda sólo el regusto amargo de un intento constructivo lastimosamente frustrado. Pocos ejemplos puede ofrecer la historia de tamaño despilfarro de tenacidad, talento y patriotismo en aras de un sistema parlamentario hueco y estéril en que los celos partidistas hacían imposible cualquier fórmula de continuidad en el esfuerzo.

Fracasada la reforma posible, la cuestión regional seguirá indisolublemente unida a la problemática española del primer tercio de siglo hasta desembocar en los estallidos revolucionarios de 1934 y 1936.

\section{NOTA BIBLIOGRAFICA}

Las disponibilidades bibliográficas sobre el tema regional, en lo que a Cataluña se refiere, han conocido en el último decenio un proceso de expansión en el doble sentido de la publicación de nuevos trabajos e investigaciones y de la recolección de materiales bibliográficos, de carácter histórico, jurídico o político, aparecidos durante la última centuria. Sin pretender enseñar nada al lector iniciado en este tipo de cuestiones, creo conveniente consignar, para los demás, una reducida relación de obras de interés del regionalismo catalán y, concretamente, del período histórico a que se extiende este trabajo.

CampS ARborx, Joaquín: Historia de la Solidaritat Catalana. Ed. Destino, Barcelona, 1970.

CARR, Raymond: España, 1808-1939. Ariel, Barcelona, 1969.

Carrera Pujals, J.: Historia politica de Cataluña en el siglo XIX. Barcelona, 1957-58. 
LA SOLIDARIDAD CATALANA ANTE LOS ENSAYOS DE REFORMA DE MAURA

Carro Martinez, Antonio: aGénesis y trayectoria de las reformas locales de Mauran, en Ideario de don Antonio Maura sobre la vida local. Instituto de Estudios de Administración Local, Madrid, 1954.

Connelly Ullman, J.: La Semana Trágica. Ariel, Barcelona, 1972.

DIARIO DE SESIONES DEL CONGRESO. Legislatura 1907.

Fernández Almagro, Melchor: Historia politica de la España contemporánea, 1897-1902. Alianza Editorial, Madrid, 1968.

Garcf́ NiEto, Carmen, y otros: Bases documentales de la España contemporánea. 5. Crisis del sistema canovista, 1898-1923. Guadiana, Madrid, 1972.

Garcf́a Venero, M.: Historia del nacionalismo catalán, 1793-1936. Madrid, 1944.

Hurtado, Amadeu: Quaranta anys d'advocat. História del meu temps. Ariel, Barcelona, 1967.

Molas, J.: La Lliga Catalana. Un estudi d'estasiologia. Edicions 62, Barcelona, 1972.

Olivar Bertrand, Rafael: Prat de la Riba. Barcelona, 1964.

Pabón, J.: Cambó. I. Edit. Alpha, Barcelona, 1952.

RosA, Tristán la: España contemporánea. Siglo XIX. Destino, Barcelona, 1972.

SABAtÉ, Modest: Historia de la Lliga. Edit. Bruguera, Barcelona, 1969.

SÁNCHEZ DE los SANTos, Modesto: Las Cortes Españolas. Las de 1907. Madrid, 1908.

SOLE-TURA, Jordi: Catalanismo y revolución burguesa. Edicusa, Madrid, 1970.

Vicéns VIVES, Jaime: Cataluña en el siglo XIX. Rialp, Madrid, 1961. 
